\title{
Towards Sustainable Environmental Policy and Management in the Fourth Industrial Revolution: Evidence from Big Data Analytics*
}

\author{
Choongik $\mathrm{CHOI}^{1}$, Chunil KIM${ }^{2}$, Chulmin $\mathrm{KIM}^{3}$ \\ Received: January 18, 2019 Revised: July 04, 2019 Accepted: July 23, 2019
}

\begin{abstract}
This study is to explore the relationship between the Fourth Industrial Revolution and the environment using the big data methodology. We scrutinize the trend of the Fourth Industrial revolution, in association with the environment, and provide implications for a more desirable future environmental policy. The results show that the Industrial Revolution has been generally perceived as negative to environment before the 2010s, while it has been widely regarded as positive after the period. It is highly expected that the Fourth Industrial Revolution will be capable of functioning as a new alternative to enhance the quality of the biophysical and social environment. This study justifies that the new wave of technological development may serve as a cure for the enhancement of the environmental quality. The positive linkage between the new technological development and the environment from this study clearly indicates that the environmental industry and environmental technologies will be key economic factors in the next-generation society. They should be of critical importance in shaping our cities into clearer and greener spaces, and people will continuously depend on the development of new environmental technologies in order to correct environmental damages.
\end{abstract}

Keywords: Environmental Management, Fourth Industrial Revolution, Big Data, Word Clouds, Association Rules.

JEL Classification Code: C55, F64, M21.

\section{Introduction}

The previous Industrial Revolutions and their resulting environmental problems have been of critical importance to the quality of life of human beings. Revolutionary movements in the manufacturing industry have been

* This work was supported by the National Research Foundation of Korea Grant funded by the Korean Government (NRF2014S1A3A2044729) and by 2017 Research Grant from Kangwon National University (No. 520170342).

1 First Author. Professor, Department of Public Administration, Kangwon National University, Republic of Korea, Email: choich@kangwon.ac.kr

2 Corresponding Author. Research Fellow, Housing Urban Finance Institute, Korea Housing \& Urban Guarantee Corporation (HUG), Busan, Republic of Korea, Email: neo1001@snu.ac.kr

3 Researcher, Institute of Social Science, Kangwon National University, Email: cmman75@gmail.com

(c) Copyright: Korean Distribution Science Association (KODISA)

This is an Open Access article distributed under the terms of the Creative Commons Attribution NonCommercial License (https://creativecommons.org/licenses/by-nc/4.0/) which permits unrestricted noncommercial use, distribution, and reproduction in any medium, provided the original work is properly cited. prevalent and widespread all over the world since the 1800s, whereas environmental problems have continuously exerted negative impacts on cities and towns around the globe. The Industrial Revolutions enabled economic growth for a few centuries, entailing significant environmental problems in large economies. As for the recent Industrial Revolution, He (2018) illustrates that the artificial intelligence plays an important role in the U.S. economy. Jung and Khoe (2018) emphasized that the Fourth Industrial Revolution results in the revolution in the agricultural sector. The blockchain technology brings about a new wave of revolution in the retail payment (Lee, Hong, \& Min, 2018). As part of major threats against mankind, environmental problems have been drastically increasing regardless of the wealth and power of a nation (Choi, 2016; Spilhaus, 1970). As countries are competing each other for the efficiency for goods distribution (Park, 2018), new technologies will shorten the processing and waiting time in the $\mathrm{B} 2 \mathrm{~B}$ (business-tobusiness) and B2C(business-to-consumer) distribution of goods. As sound and sustainable environmental management becomes important in management and 
distribution sectors (Ma, Choi, \& Ahn, 2017), the Fourth Industrial Revolution can enhance the Eco-friendly production in every corner of industry.

The Fourth Industrial Revolution will be able to have a critical influence on built environment, as well as mankind itself in every corner of our society. At the 2016 Davos, the World Economic Forum pointed out that the Fourth Industrial Revolution will be accompanied by a high level of automation and connectivity, which will eventually bring changes to many forms of lifestyle throughout the world (Schwab, 2016). Figure 1 exhibits the result of Google trend searches after 2004 on the Fourth Industrial Revolution. It presents that the trend of public opinion moved up and down with a relatively smaller volatility before 2016 . The Fourth Industrial Revolution has however been drawing much greater attention since 2016.

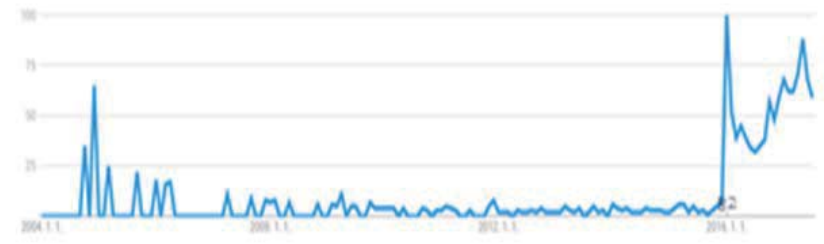

Source: Authors' calculation

Figure 1: The Trend of the Fourth Industrial Revolution (2004-2017)

It is important to understand the relationship between the Industrial Revolution and environmental problems. In particular, would people think that the recent technological developments harm the environment? Or, would people think that the development could serve as the protective factor against environmental contamination and deterioration? This study is to explore whether there has been any pivotal change in the recognition on the relationship between the Industrial Revolution and the environment. Specifically, it focuses on how the assumed relationship that is reflected in the (online) newspaper articles has changed over the last three decades (19902017). We utilized a data-mining methodology to excavate the perception on the relationship from the flows of media reports, which contain ideas and opinions daily updated from ordinary people.

This paper starts with looking briefly at the history on the relationship between the Industrial Revolution and environmental degradation. The paper then presents how our big-data methodology is applied to mine the relationship from the online data sources in the Methodology and Data chapter. Next, the paper discusses some interesting results from the word clouds and keyword networking procedures. Finally, it concludes with important perspectives and implications on how our society will evolve and on how the society should be prepared in the era of the new Industrial Revolution.

\section{The Relationship between Industrial Revolution and Environmental Pollution}

The use of fossil fuels has drastically increased since the First Industrial Revolution. In order to generate electricity, power plants should burn those fossil fuels, producing hazardous environmental pollutants in industrialized countries. Those countries generally operate power plants and factories significantly. There are also many cars and big cities in the countries, which contribute to pollutant emission.

The reason why our society cares about the existence of big cities is that it is important to understand the spatial nature of cities: cities are dense. The vulnerability to urban disaster damages, in a sense, originates from denser spatial configuration. The concentration of the capital assets, population, and urban functions on the dense areas has been thought as one of the main factors exacerbating urban disaster vulnerability and resilience. Residents, who live in denser cities with crowded living conditions, are more exposed to disaster risk, making cities vulnerable to manmade natural disasters (Pelling, 2007).

The linkage between urbanization and disaster vulnerability should be thoroughly investigated in identifying the determinants of urban disaster and damage. There exists a feedback mechanism between the changes in population and land use. Population causes the changes in land use, and land use inevitably affects the locational pattern of population. One should understand better the dynamic relationship in order to investigate the major factors on how and why urban disasters occur. There has been a significant amount of studies trying to decouple the linkage. Different studies have reached different conclusions when it comes to how the interaction between these two factors affects disaster damage.

It is the Industrial Revolution that shifted the traditional manufacturing to a cost-efficient system. Prior to the Industrial Revolution, manufacturing was mainly done in residential environments, using hand tools or basic machines. Industrialization resulted in significant changes in the manufacturing sector. The textiles industry was mostly affected in this era (Landes, 2003). Not only did technological advances occur, but societal revolution emerged, covering the protection of property rights, entrepreneurial spirit, and consumer revolution. Those elements helped expand industrialization in Britain, Belgium, the United States, and France (Ray, 1998). The revolution was in line with revolution in the agricultural sector, directing 
surplus agricultural labor force to the industrialized manufacturing sector.

Building upon the First Industrial Revolution, the Second Industrial Revolution occurred between 1840 and 1870. The technological and economic progress in this era encompassed the steam transportation (such as steampowered railways, boats, and ships), allowed technological and economic progress to continue (Hunter,1985; Taylor, 1951; Wickham, 1926). The level of automation increased, and steel industry benefitted the most from the revolution. Petroleum and electricity were the main power sources as engines were operated by internal combustion. Inventions and innovations on automobiles, chemicals, railroads, and telecommunication exploded.

During the First and Second Industrial Revolution periods, environmental pollution was the most significant cost in exchange of technological advancement and the resulting expansion of wealth. According to Engels (2009), cities were tainted by thick black smoke, and urban slums suffered from disease and death. A recent study by Hanlon (2016) concluded that local industrial pollution related to the coal use brings about a significant amount of costs to local economic growth. This result is an important empirical evidence that residents in denser urban places located around manufacturing sites and plants, which emanate a large amount of chemical agents, are at higher environmental risk compared with residents in remote locations from the city centers.

The Third Industrial Revolution introduced more efficient tools and methods via information technology, such as automated machines and robots. The process of manufacturing has been digitized. The digitalization is going beyond its boundary: the mode of communication expands to a digitized renewable Energy Internet, a digitized automated Transportation and Logistics internet, and finally the Internet-of-Things (IOT), whereas the infrastructure in the 20th century was merely the combination of centralized electricity - the telephone, radio and television, and national road networks. One of the most important elements in this era is the near-zero marginal production cost (Rifkin, 2015). The cost of producing and delivering the information goods falls to near-zero. In addition, consumers turn into producers: they produce the own contents and publish them on internet web pages, sometimes for profit. Nowadays, the Fourth Industrial Revolution is characterized as a wave of new technological development and innovation in driverless mode of transportation, smart robotics, materials that become lighter and tougher, and efficient manufacturing processes via 3D printing (Elliott, 2016).

The first three periods of Industrial Revolutions caused some serious environmental problems (Swanborough, 2017). Ninety-two percent of the world's population are exposed to unsafe levels of air pollution. The past industrialization periods have resulted in abnormal climate changes, the depletion of natural resources, the spread of pollutants in rivers and soils, and deforestation. Can these problems actually be fixed in the era of the Fourth Industrial Revolution? Is our society facing a new threat? We want to explore whether or not the new wave of revolution can provide efficient and effective remedies for environmental degradation, which is a notorious legacy from the previous Industrial Revolution periods.

Aside from the environmental issues, the information overload itself could be also problematic. As Swanborough (2017) denotes, some of those who do not have access to the information infrastructure could go astray and be isolated in any decision-making process from others. A system is intrinsically composed of numerous interacting and fast-moving parts. Thus, a system or a platform could turn into a complete failure as a whole, whereas each discrete element proceeds with the on-going path without realizing the common goal.

\section{Methodology and Data}

\subsection{Big data methodology}

In order to explore the association between the Industrial Revolution and the environment in their social and historical contexts, this study has employed a big data analytic methodology. The term, "big data", is a terminology for data sets that are so large that traditional data processing is not enough to deal with them properly. They can be structured or unstructured, multi-faceted, and multi-dimensional. The main reason for the recent expansion of the big data is that recently developed high-tech devices and outlets make data collection much easier. Those are various and numerous Internet of Things (IOT) devices such as cell phones, remote sensing and closed-circuit television, and other wireless sensor networks. Big data analytics in general include capturing data, data mining, data storage, data analysis, searching, and visualization.

Researchers, using the big data methodology, try to discover patterns, correlations, and other insights from enormous amounts of information, which take numeric and/or text formats. The big data analytic technologies enable us to find valuable information swiftly and systematically, as opposed to the traditional data processing methods. Ultimately, big data analytics help us identify new opportunities.

As a big-data analytic method, this study adopted textmining technologies, which are word clouds and association rules. Text-mining methods help us analyze text data over 

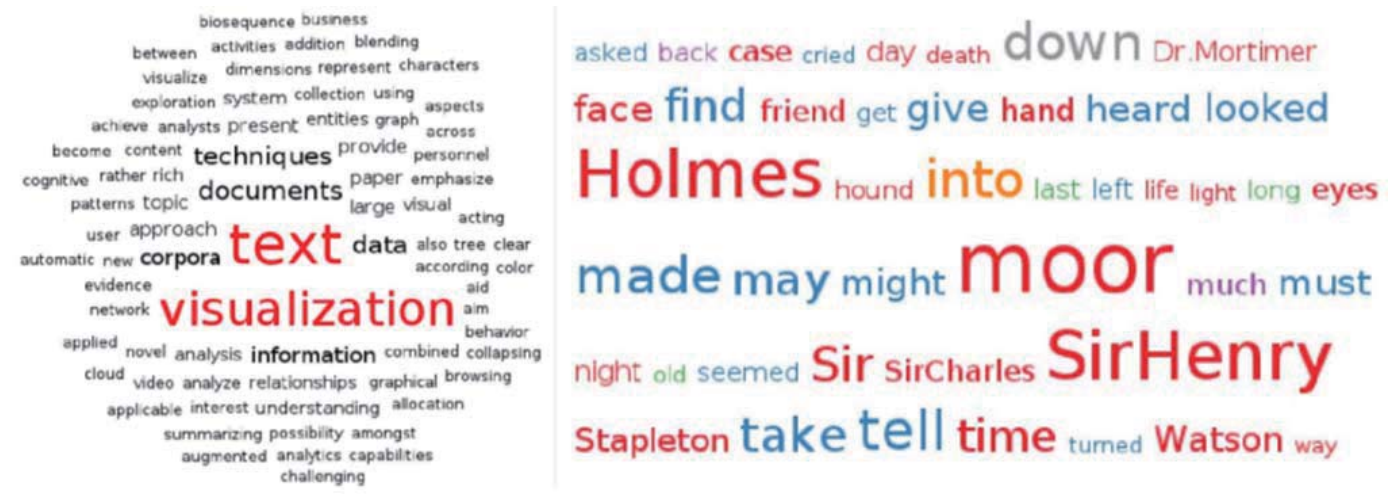

Source: Heimerl, Lohmann, Lange \& Ert (2014).

Figure 2: The trend of the Fourth Industrial Revolution (2004-2017)

the web, electronic books, and other text-based sources, making us get some new insights that we have not noticed before. In order to uncover the relationships between topics and terms, text mining usually uses the machine-learning technology to analyze a great deal of information and data. Specifically, the 'word clouds' method is a graphical representation of word frequency. Once we excavate frequently used words from a body of text, we proceed with further analyses to find patterns of interest. In other words, the method helps to figure out whether or not a given term is relevant to specific information (Heimerl, Lohmann, Lange, \& Ert, 2014).

Word clouds have been utilized as a visually appealing tool for text mining. They are used to provide comments by compressing texts into words that appear with the highest frequency. Basically, this is conducted like a simple text summarization. The study tries to explore the usefulness of the words summarized via word clouds by applying the association rules (Heimerl, Lohmann, Lange, \& Ert, 2014).

The association rules specify patterns found in the relationships among items. While association rules are composed of subsets of upper item sets, they are not used for prediction, but used for unknown findings in big data materials (Lantz, 2015). Association rules are principally based on two statistical measures: support and confidence measures. The support rule measures how frequently it appears in the data. A function defining support for the item set, $X=\{A, B\}$, can be defined as the following formula: $\mathrm{P}(\mathrm{A} \cap \mathrm{B})=\mathrm{X} / \mathrm{N}$. Here, $\mathrm{N}$ is the total number of articles in the database and count $(X)$ is the number of articles containing item set $\{A, B\}$. For instance, if the item set $\{A, B\}$ has the support of 0.4 in the Industrial Revolution data, we expect that $\mathrm{A}$ and $\mathrm{B}$ simultaneously appear in forty percent of the total articles.

On the other hand, the confidence rule measures the predictive power and accuracy. It can be defined as the support of the item set containing both $\mathrm{A}$ and $\mathrm{B}$, divided by the support of the item set containing only $A$. Also, it is expressed as $\mathrm{P}(\mathrm{B} \mid \mathrm{A})=\mathrm{P}(\mathrm{A} \cap \mathrm{B}) / \mathrm{P}(\mathrm{A})$. In fact, support $(A, B)$ is the same as $P(A \cap B)$ and confidence $(A \rightarrow B)$ is the same as $P(B \mid A)$. The confidence provides the proportion of appearance, which examines how the presence of $\mathrm{A}$ affects the presence of $\mathrm{B}$. It should be noted that the confidence that A leads to B is not the same as the confidence that $\mathrm{B}$ leads to $\mathrm{A}$. In general, the higher the support and confidence are, the stronger is the association between both items. The derived information from the method described above should be useful to understand the trending status-quo of the perception on the relationship between industrial revolution and environment.

Another association rule is called the "lift" and is defined as the following term: $\mathrm{P}(\mathrm{B} \mid \mathrm{A}) / \mathrm{P}(\mathrm{B})$. Similar to the support and confidence, the lift indicates the degree of connectivity between $\mathrm{A}$ and $\mathrm{B}$. It can be measured by the ratio between the confidence values of $\mathrm{P}(\mathrm{B} \mid \mathrm{A})$ and $\mathrm{P}(\mathrm{B})$. The lift value identifies the comparative importance of $A$ because it is of the comparison between the probability that $\mathrm{B}$ appears as A appears and the probability that B appears by itself as A does not appear. In this regard, the lift method is to examine how much A affects B. In general, if the value of lift is greater than 1, we can conclude that the words are significantly associated.

\subsection{Data}

This study uses (online) newspaper articles collected from the Naver News Library and Naver Newsstand, where "industrial revolution" and "environment" are searched in the Naver website. Naver is a South Korean web portal operated by Naver Corporation. Many online users in Korea use Naver as a hub where they read news, acquire daily-life information, and communicate in online clubs. From the 
perspective of this multi-dimensional functionality, Naver outperforms Google in Korea.

The analysis period of this research consists of 6 periods, which covers the 28-year span from 1990 to 2017. The total number of news articles is 9,588 as shown in Table 1. Figure 3 shows that the number of articles has been increasing steadily since 1990, and dramatically since 2016. According to the data in Table 1, the newspaper articles that contain the Industrial Revolution and the environment are published most frequently in Period 6.

Table 1: The trend of searches for the Fourth Industrial Revolution (2004-2017)

\begin{tabular}{|c|c|c|c|c|c|c|c|}
\hline $\begin{array}{c}\text { Period } \\
\text { (year) }\end{array}$ & $\begin{array}{c}\text { Period } \\
1 \\
(1990- \\
1994)\end{array}$ & $\begin{array}{c}\text { Period } \\
2 \\
(1995- \\
1999)\end{array}$ & $\begin{array}{c}\text { Period } \\
3 \\
(2000- \\
2004)\end{array}$ & $\begin{array}{c}\text { Period } \\
4 \\
(2005- \\
2009)\end{array}$ & $\begin{array}{c}\text { Period } \\
5 \\
(2010- \\
2014)\end{array}$ & $\begin{array}{c}\text { Period } \\
6 \\
(2015- \\
2017)\end{array}$ & Total \\
\hline $\begin{array}{l}\text { Number } \\
\text { of } \\
\text { articles }\end{array}$ & 58 & 67 & 180 & 941 & 1,459 & 6,883 & 9,588 \\
\hline
\end{tabular}

Source: Authors' calculation

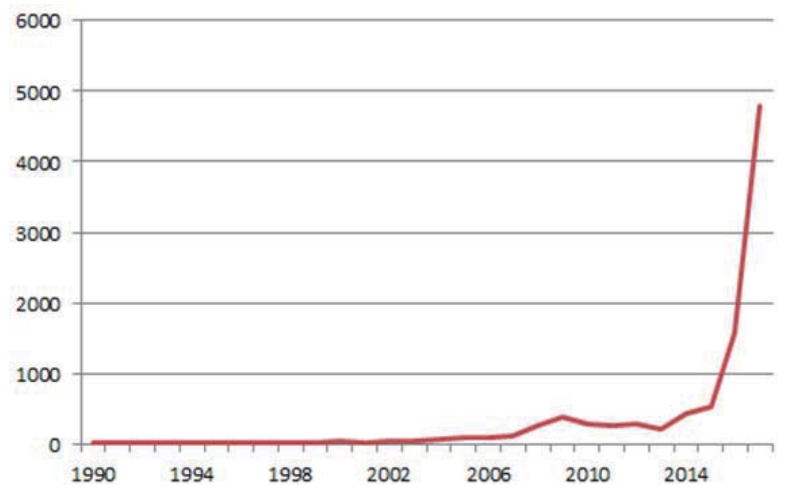

Source: Authors' calculation

Figure 3: The trend of the number of articles with 'Industrial Revolution' and 'environment'

\section{Results}

The big data analysis of this study is conducted in two stages, which include word clouds and the application of association rules. The word clouds as the first analysis tool are applied to the 9,588 articles. The results of word clouds in each period are shown in Figure 4. It shows that words of high frequency are 'technology' and 'industry'.

\begin{tabular}{|c|c|c|}
\hline 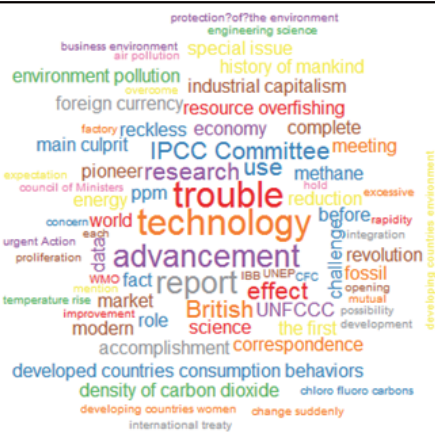 & 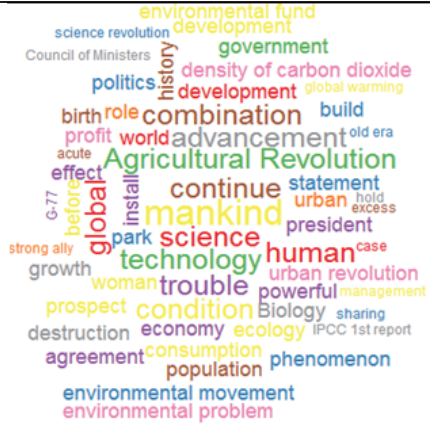 & 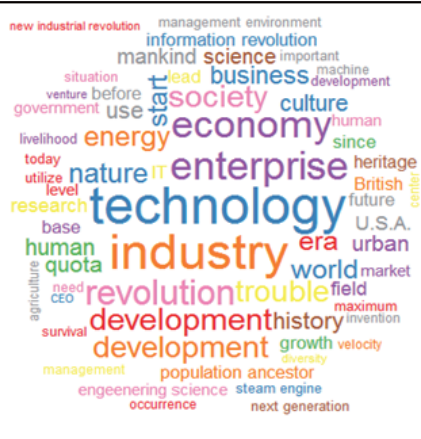 \\
\hline Period 1 (1990-1994) & Period 2 (1995-1999) & Period 3 (2000-2004) \\
\hline 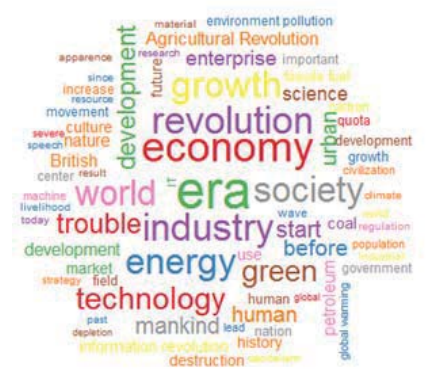 & 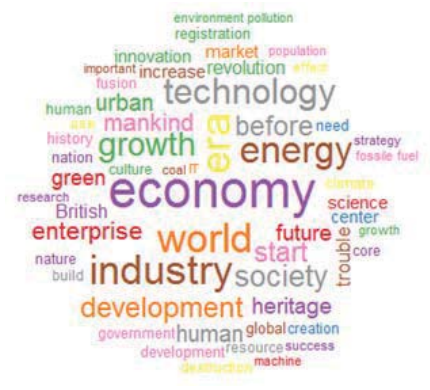 & 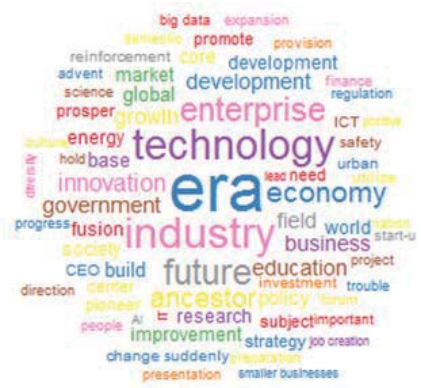 \\
\hline Period 4 (2005-2009) & Period 5 (2010-2014) & Period 6 (2015-2017) \\
\hline
\end{tabular}

Source: Authors' calculation

Figure 4: The results of word clouds in the each period 
It suggests that the Industrial Revolution is usually linked to the two words in the news reports for the last 28 years in Korea. It is interesting that words of high frequency used in the 1990s are different from those of high frequency in the 2010s. In the 1990s, the Industrial Revolution has been going together with negative words such as 'pollution', 'resource overfishing', and 'reduction', whereas it has been going together with some positive words such as 'innovation', 'growth', and 'improvement' since the 2010s. This suggests that people's perceptions on the technological development have been shifted from negative to positive when it comes to the relationship between the Industrial Revolution and the environment. We could expect that economic growth and development in the era of the Fourth Industrial Revolution would not necessarily be the factors that cause the deterioration and devastation of the natural environment.
The analysis of keywords networking by period illustrated how keywords play a significant role in the change of word networking over time. The results indicate that the network between keywords is sporadic, changing with the size and color of circle. Further, the inflow keywords are highly likely to produce strong connections with the Industrial Revolution in the newspaper articles.

Table 2 shows that the Industrial Revolution has been in negative association with the environment in periods 1-2. The 'pollution' and 'destruction' frequently appears with a high lift value, which means the strong association between words. According to the analysis results, it is inferred that the Industrial Revolution has made negative impacts on the environment in terms of an environmental quality of earth in history.

Table 2: The results of association rules

\begin{tabular}{|c|c|c|c|c|c|c|c|}
\hline \multicolumn{4}{|c|}{ Period 1: 1990-1994 } & \multicolumn{4}{|c|}{ Period 2: 1995-1999 } \\
\hline rules & support & confidence & lift & rules & support & confidence & lift \\
\hline$\{I R\}=>\{$ change $\}$ & 0.050 & 0.209 & 1.013 & $\{I R\}=>\{$ innovation $\}$ & 0.072 & 0.230 & 0.466 \\
\hline$\{\mathrm{IR}\}=>\{$ advance $\}$ & 0.045 & 0.186 & 1.514 & $\{\mathrm{IR}\}=>\{$ world $\}$ & 0.071 & 0.226 & 1.258 \\
\hline$\{I R\}=>\{$ economy $\}$ & 0.045 & 0.186 & 1.051 & $\{I R\}=>\{$ energy $\}$ & 0.065 & 0.206 & 1.325 \\
\hline$\{\mathrm{IR}\}=>\{$ mankind $\}$ & 0.039 & 0.163 & 3.642 & $\{I R\}=>\{$ growth $\}$ & 0.058 & 0.182 & 0.735 \\
\hline$\{I R\}=>\{\operatorname{man}\}$ & 0.039 & 0.163 & 2.428 & $\{I R\}=>\{$ change $\}$ & 0.056 & 0.179 & 1.210 \\
\hline$\{I R\}=>\{$ use $\}$ & 0.034 & 0.140 & 3.568 & $\{I R\}=>\{$ economy $\}$ & 0.055 & 0.176 & 1.037 \\
\hline$\{I R\}=>\{$ nature $\}$ & 0.034 & 0.140 & 2.498 & $\{\mathrm{IR}\}=>\{$ green $\}$ & 0.051 & 0.162 & 0.579 \\
\hline$\{\mathrm{IR}\}=>\{$ earth $\}$ & 0.034 & 0.140 & 2.081 & $\{I R\}=>\{$ earth $\}$ & 0.048 & 0.152 & 1.830 \\
\hline$\{I R\}=>\{$ problem $\}$ & 0.034 & 0.140 & 1.784 & $\{I R\}=>\{$ president $\}$ & 0.042 & 0.132 & 1.933 \\
\hline$\{I R\}=>\{$ pollution $\}$ & 0.028 & 0.116 & 2.602 & $\{\mathrm{IR}\}=>\{$ problem $\}$ & 0.040 & 0.128 & 1.651 \\
\hline \multicolumn{4}{|c|}{ Period 3: 2000-2004 } & \multicolumn{4}{|c|}{ Period 4: 2005-2009 } \\
\hline rules & support & confidence & lift & rules & support & confidence & lift \\
\hline$\{I R\}=>\{$ earth $\}$ & 0.224 & 0.481 & 1.862 & $\{I R\}=>\{$ earth $\}$ & 0.119 & 0.320 & 2.382 \\
\hline$\{I R\}=>\{$ destruction $\}$ & 0.138 & 0.296 & 1.719 & $\{I R\}=>\{\operatorname{man}\}$ & 0.104 & 0.280 & 2.345 \\
\hline$\{I R\}=>\{$ development $\}$ & 0.103 & 0.222 & 1.289 & $\{I R\}=>\{$ life $\}$ & 0.075 & 0.200 & 2.680 \\
\hline$\{I R\}=>\{$ industry $\}$ & 0.103 & 0.222 & 0.716 & $\{I R\}=>\{$ mankind $\}$ & 0.075 & 0.200 & 2.680 \\
\hline$\{I R\}=>\{$ developed country $\}$ & 0.086 & 0.185 & 1.534 & $\{I R\}=>\{$ destruction $\}$ & 0.075 & 0.200 & 2.233 \\
\hline$\{I R\}=>$ history $\}$ & 0.069 & 0.148 & 2.148 & $\{\mathrm{IR}\}=>$ period $\}$ & 0.060 & 0.160 & 2.680 \\
\hline$\{I R\}=>\{$ beginning $\}$ & 0.069 & 0.148 & 1.719 & $\{I R\}=>\{$ nature $\}$ & 0.060 & 0.160 & 2.144 \\
\hline$\{\mathrm{IR}\}=>\{$ world $\}$ & 0.069 & 0.148 & 1.432 & $\{I R\}=>\{$ civilization $\}$ & 0.060 & 0.160 & 2.144 \\
\hline$\{I R\}=>\{$ century $\}$ & 0.052 & 0.111 & 2.148 & $\{\mathrm{IR}\}=>\{$ society $\}$ & 0.060 & 0.160 & 1.340 \\
\hline \multicolumn{4}{|c|}{ Period 5: 2010-2014 } & \multicolumn{4}{|c|}{ Period 6: 2015-2019 } \\
\hline rules & support & confidence & lift & rules & support & confidence & lift \\
\hline$\{I R\}=>\{$ world $\}$ & 0.051 & 0.198 & 1.334 & $\{I R\}=>\{$ change $\}$ & 0.252 & 0.362 & 1.183 \\
\hline$\{I R\}=>\{$ change $\}$ & 0.048 & 0.187 & 1.008 & $\{I R\}=>\{$ industry $\}$ & 0.161 & 0.231 & 1.082 \\
\hline$\{\mathrm{IR}\}=>\{$ industry $\}$ & 0.047 & 0.183 & 1.089 & $\{I R\}=>\{$ future $\}$ & 0.142 & 0.204 & 1.150 \\
\hline$\{I R\}=>\{$ earth $\}$ & 0.045 & 0.172 & 2.495 & $\{I R\}=>\{$ response $\}$ & 0.122 & 0.175 & 1.332 \\
\hline$\{I R\}=>\{$ energy $\}$ & 0.042 & 0.160 & 1.166 & $\{I R\}=>\{$ technology $\}$ & 0.108 & 0.156 & 1.066 \\
\hline$\{\mathrm{IR}\}=>\{$ economy $\}$ & 0.036 & 0.138 & 1.168 & $\{I R\}=>\{$ world $\}$ & 0.082 & 0.118 & 1.036 \\
\hline$\{I R\}=>\{$ green $\}$ & 0.036 & 0.138 & 1.014 & $\{I R\}=>\{$ society $\}$ & 0.071 & 0.102 & 1.127 \\
\hline$\{I R\}=>\{$ beginning $\}$ & 0.034 & 0.131 & 1.797 & $\{\mathrm{IR}\}=>\{$ open $\}$ & 0.070 & 0.101 & 1.221 \\
\hline
\end{tabular}

Note: IR refers to Industrial Revolution

Source: Authors' calculation 
From period 3 and onwards, the number of articles with negative words has been constantly diminishing since 2000 . The words 'pollution' and 'problem' begin to be substituted by the words 'advancement' and 'growth'. The latter words have rarely appeared with the technological and industrial development.

There has been a noticeable change in period 4. The words 'energy' and 'green' begin to arise more often. We consider this result a drastic shift in terms of the linkage of the technological and industrial advancement to the environmental protection and ecological welfare. In the advent of a new industrial revolution, people seem to recognize that the revolution in fact would make a positive contribution to the improvement in the quality of the environment.

\section{Discussion and Conclusion}

This study examined how the Industrial Revolution has been associated with various connotations for environmental quality over time. We found that the Industrial Revolution in general has been implicitly regarded as having negative environmental effects. The analytic results however show that the Industrial Revolution tends to be associated with positive environmental implications since the 2010s, while during and before the 1990s, it is more likely to imply degradation in the quality of the natural environment.

The association between the Industrial Revolution and the environment may function as a double-edged sword. Although the technological development has made a positive contribution to the human welfare, the environment has often been degraded due to the overuse of fossil fuels, deforestation, and chemical pollution. As the flip side, the new wave of technological development may serve as a cure for the enhancement of the environmental quality. Indeed, technologies are in place in ecofriendly waste management, waste-to-energy power plants, and pollutantsreducing modes of transportation. The positive linkage between the new technological development and the environment from this study clearly indicates that the environmental industry and environmental technologies will be the key economic factors in the next-generation society. They should be of critical importance in shaping our cities into clearer and greener spaces, and people will continue to depend on the new environmental technologies in order to correct environmental damages. It is expected that the Fourth Industrial Revolution will be able to play a significant role in improving (not deteriorating) the environment. Specifically, the application of technological innovation based on the Fourth Industrial Revolution enables us to reduce and control environmental pollution, bringing us to the environmentally sound and sustainable state. The IoT, green nano-tech manufacturing, and $3 D$ printing are emerging as technological solutions to the improvement and enhancement of the environmental quality.

Large quantities of data are generated by smart phone, PC, and electrical appliances, in which GPS or electronic sensors produce various kinds of data such as text, picture, voice, etc. The IoT technology allows policy practitioners and authorities to collect the necessary data for environmental protection via the electronic chips and sensors embedded in things. Monitoring system based on IoT will be able to play an important role in disaster prevention and environmental conservation. Unmanned monitoring system automatically senses environmental and manmade disasters with cloud-computing technologies, which provides highly efficient big-data analysis with lower costs. Generated from internet platforms (such as Facebook, Twitter, or YouTube), smartphone, and IoT are big data, which need new methods to be analyzed. Further, big-data generated by high-level technology can be applied to the optimization in goods production, economic development, and societal networking. Through the technological development, the balance between supply of and demand for energy can be achieved. Monitoring system against disasters will be efficiently and effectively operated, resulting in the safer living environment. Additionally, industries in the new era based on high technology with high energy efficiency will make a significant contribution to the reduction of the emission of gases such as carbon dioxide.

On the contrary, the Fourth Industrial Revolution is more likely to increase the interactive complexity, leading to unavoidable "normal accidents". According to Perrow (1999), highly complex systems, such as nuclear power plants and space shuttles, are characterized by high dependency and interactions among numerous constituent parts. For such a system to work, each of those parts and the interrelationships across them are required to fulfill the functions as intended by the original engineering design. Although the probability that one part of the system works properly is very high, the whole system would become vulnerable to the failure and malfunction. It is because the working of the system itself depends on the proper working of each and every interactive part of the system. Thus, exploring innovative ways of dealing with some new risks and coping with emerging unknown threats should be considered in the new wave of the technological innovation. It is important for us to maximize the advantages and benefits derived from the Fourth Industrial Revolution. And it is more important to be on full alert to unintended negative consequences that the Revolution brings to us. 


\section{References}

Choi, C. (2016). Does economic growth really reduce disaster damages? Index decomposition analysis for the relationship between disaster damages, urbanization and economic growth. International Journal of Urban Sciences, 20(2), 188-205.

Elliott, L. (2016). Fourth Industrial Revolution brings promise and peril for humanity. Guardian. Retrieved August 18, 2017, from https://www.theguardian.com/business/ economics-blog/2016/jan/24/4th-industrial-revolutionbrings-promise-and-peril-for-humanity-technology-davos.

Engels, F. (2009). The Condition of the Working Class in England. London, England: Penguin Classics.

Hanlon, W. W. (2016). Coal Smoke and the Costs of the Industrial Revolution (No. w22921). National Bureau of Economic Research.

He, Y. (2018). A study on the impact of artificial intelligence industry on macroeconomy: Evidence from United States of America. East Asian Journal of Business Management, 8(4), 37-44.

Heimerl, F., Lohmann, S., Lange, S., \& Ert. T. (2014). Word cloud explorer: Text analytics based on word clouds. 47th Hawaii International Conference on System Science, 1833-1842.

Hunter, E. J. (1985). Computerized Cataloguing. London, England: Clive Bingley.

Jung, J.-S., \& Khoe, K. (2018). The strengthening of export competitiveness through the 6th agriculture industrialization and the 4th Industrial Revolution. Journal of Industrial Distribution \& Business, 9(3), 31-43.

Landes, D. S. (2003). The Unbound Prometheus: Technological Change and Industrial Development in Western Europe from 1750 to Present. Cambridge, England: Cambridge University Press.

Lantz, B. (2015). Machine Learning with R. Birmingham, England: Packt Publishing.
Lee, W.-J., Hong, S.-T., \& Min, T. (2018). Bitcoin distribution in the age of digital transformation: Dual-path approach. Journal of Distribution Science, 16(12), 47- 56.

Ma, J.-H., Choi, S.-B., \& Ahn, Y.-H. (2017). The impact of eco-friendly management on product quality, financial performance and environmental performance. Journal of Distribution Science, 15(5), 17-28.

Park, Y.-K. (2018). Performance analysis of preprocessing algorithm in container terminal and suggestion for optimum selection. Journal of Distribution Science, 16(12), 95-104.

Pelling, M. (2007). Learning from others: the scope and challenges for participatory disaster risk assessment. Disasters, 31(4), 373-385.

Perrow, C. (1999). Normal Accidents: Living with High-Risk Technologies. Princeton, NJ: Princeton University Press.

Ray, K. (1998). Industrialization and Development: A Comparative Analysis. London, England: UGL Press.

Rifkin, J. (2015). Welcome to the Third Industrial Revolution. Wharton Magazine.

Schwab, K. (2016). The 4th Industrial Revolution. World Economic Forum. Retrieved November 16, 2017, from https://www.weforum.org/agenda/2015/10/will-the-fourthindustrial-revolution-have-a-human-heart-and-soul.

Spilhaus, A. (1970). The next industrial revolution. Science, 167(3926), 1673-1673.

Swanborough, J. (2017). Old industrial revolutions broke the environment. Can the new one fix it? African Independent. Retrieved May 5, 2017, from https://www.africanindy.com/wef-africa/old-industrialrevolutions-broke-the-environment-can-the-new-one-fix-it8952517.

Taylor, G. R. (1951). The Transportation Revolution (pp.1815-1860). Abingdon, England: Routledge.

Wickham, J. (1926). English and American Tool Builders. London, England: McGraw-Hill. 